\title{
Chilled Mirror Dew Point Hygrometer Handbook
}

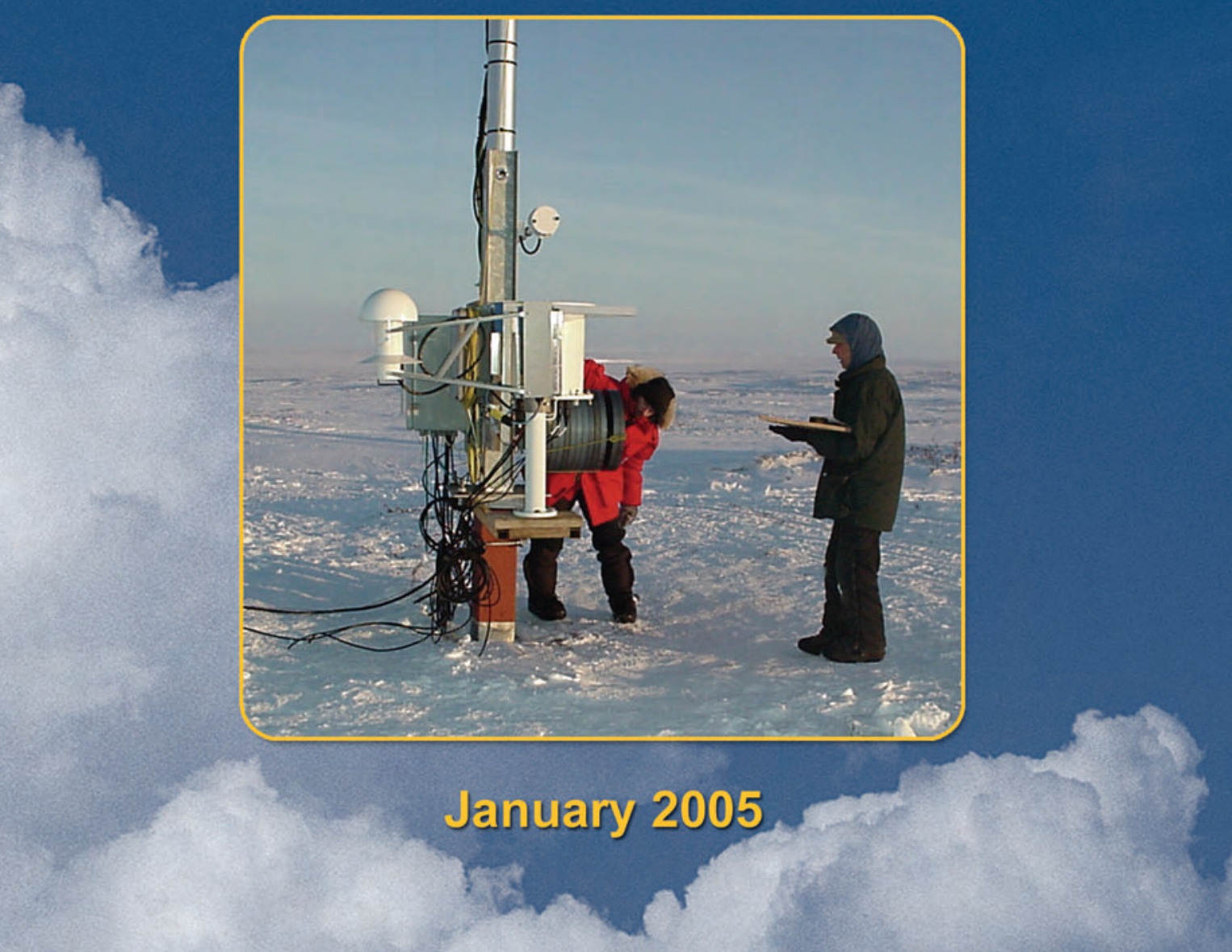




\section{Chilled Mirror Dew Point Hygrometer (CM) Handbook}

January 2005

M.T. Ritsche

Work supported by the U.S. Department of Energy, Office of Science, Office of Biological and Environmental Research 


\section{Contents}

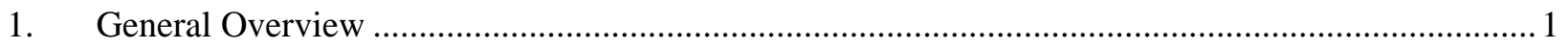

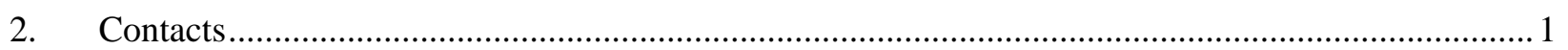

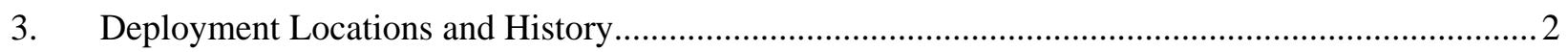

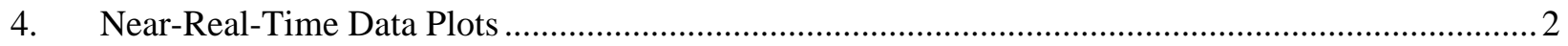

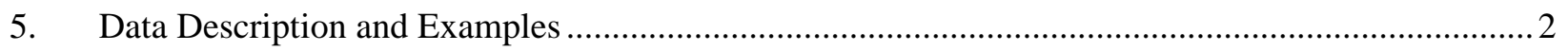

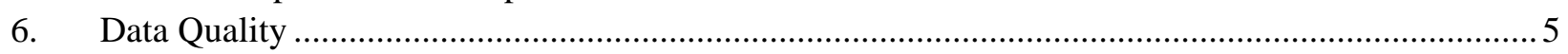

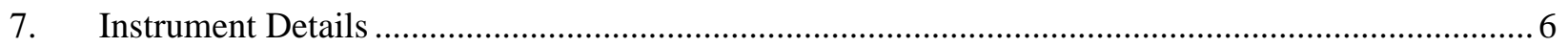

Figures

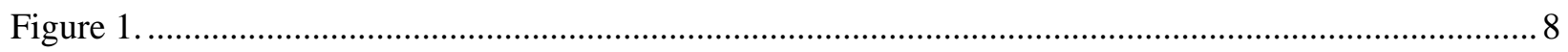

\section{Tables}

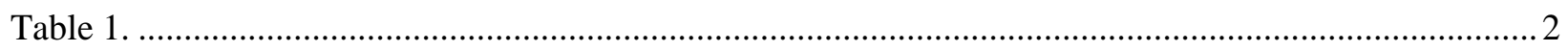

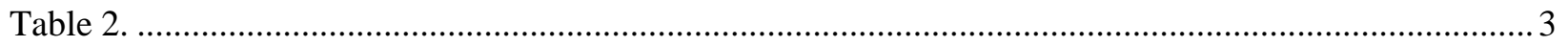

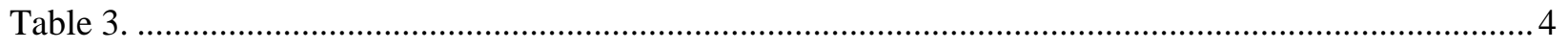

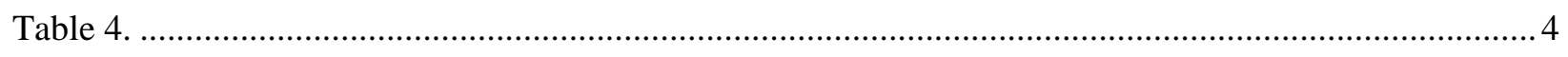

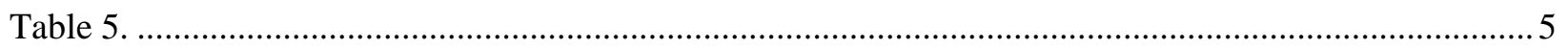




\section{General Overview}

Important Note to CM Data Users: Chilled mirror (CM) moisture and temperature measurements may not be representative of the true atmospheric state because the observations are made inside a large mailbox aspirator. The aspirator is used to equilibrate radiosondes with the atmosphere before launch, and the CM observations are designed to be used for radiosonde scaling. Due to the physical size of the mailbox aspirator, the temperature and relative humidity inside the aspirator box will be different from the free atmosphere. During the day, the temperature inside the box may be too high owing to solar heating, which will result in an anomalously low relative humidity. The opposite may be true at night. Calculating a dew point from the temperature and relative humidity should result in an accurate moisture measurement, but this assumes several things that may or may not be true at any given time. Therefore, it is recommended that measurements from the CM system be used with caution. Please contact the instrument mentor with any questions as to the validity and applicability of the CM data.

The $\mathrm{CM}$ systems have been developed for the ARM Program to act as a moisture standard traceable to National Institute of Standards and Technology (NIST). There are three CM systems that are each fully portable, self-contained, and require only $110 \mathrm{~V}$ AC power. The systems include a CM sensor, air sampling and filtration system, a secondary reference (Rotronic HP043 temperature and relative humidity sensor) to detect system malfunctions, a data acquisition system, and data storage for more than one month of 1-minute data. The CM sensor directly measures dew point temperature at $1 \mathrm{~m}$, air temperature at $2 \mathrm{~m}$, and relative humidity at $2 \mathrm{~m}$. These measurements are intended to represent self-standing data streams that can be used independently or in combinations

One CM was installed at the Southern Great Plains (SGP) Central Facility (CF) Balloon-Borne Sounding System (BBSS) location for continuous operation. There are a total of three CM systems available for use in field campaigns and special projects. For example, CMs were located on the CF 60-m tower at 25 and $60 \mathrm{~m}$ during field campaigns.

The CM system uses a General Eastern Instruments D2/E4 combination system with a dew point inaccuracy of approximately $+/-0.1$ to $0.2^{\circ} \mathrm{C}$. The response time of the system is roughly 5 minutes due to the sampling system and it has a maximum dew point depression of about $65^{\circ} \mathrm{C}$.

\section{Contacts}

\subsection{Mentor}

Mike Ritsche

Argonne National Laboratory

9700 South Cass Avenue

Argonne, IL 60439

Phone: 630-252-1554

mtritsche@anl.gov 


\subsection{Instrument Developer}

Chilled Mirror System:

General Eastern, Inc.

20 Commerce Way

Woburn, MA 01801

Phone: $781-938-7070$ or $800-225-3208$

Fax: 781-938-1071

www.protimeter-usa.com/geiindex.html

Rotronic T\&RH sensor:

Rotronic Instrument Corp.

160 East Main Street

Huntington, NY 11743

Phone: 631-427-3898

Fax: 631-427-3902

www.rotronic-usa.com

Datalogger:

Campbell Scientific, Inc.

815 West 1800 North

Logan, UT 84321

Phone: 801-753-2342

Fax: 801-750-9540

3. Deployment Locations and History

Table 1.

\begin{tabular}{|c|c|c|c|}
\hline Location & Date Installed & Date Removed & Status \\
\hline SGP CF & $04 / 1998$ & $08 / 2003$ & Removed \\
\hline
\end{tabular}

4. Near-Real-Time Data Plots

This section is not applicable to this instrument.

\section{Data Description and Examples}

This section is not applicable to this instrument.

\subsection{Data File Contents}

\subsubsection{Primary Variables and Expected Uncertainty}

The CM sensor directly measures: 
- Dew point temperature at $1 \mathrm{~m}$, Precision: $0.1 \mathrm{C}$; Uncertainty: approximately $0.5 \mathrm{C}$.

- Air temperature at 2 m, Precision: 0.01 C; Uncertainty: a function of wind speed (see Definition of Uncertainty, Section 5.1.1.1)

- Relative humidity at 2 m, Precision: $0.1 \%$ RH; Uncertainty: +/-3\% RH ( $0 \%$ to $100 \%$ RH).

Table 2.

\begin{tabular}{|c|c|c|c|c|c|}
\hline Quantity & Variable & Unit & $\begin{array}{c}\text { Measurement } \\
\text { Level }\end{array}$ & $\begin{array}{c}\text { Measurement } \\
\text { Interval }\end{array}$ & Resolution \\
\hline $\begin{array}{c}\text { Dew Point } \\
\text { Temperature }\end{array}$ & td & C & $1 \mathrm{~m}$ & $1 \mathrm{~min}$ & 0.01 \\
\hline Air Temperature & temp & $\mathrm{C}$ & $1 \mathrm{~m}$ & $1 \mathrm{~min}$ & 0.1 \\
\hline Relative Humidity & $\mathrm{rh}$ & $\%$ & $1 \mathrm{~m}$ & $1 \mathrm{~min}$ & 1 \\
\hline
\end{tabular}

\subsubsection{Definition of Uncertainty}

Uncertainty is the range of probable maximum deviation of a measured value from the true value within $95 \%$ confidence limits. It is defined as the square root of the sum of all random errors squared plus the square root of the sum of all bias errors squared. The errors are assumed to be statistically independent.

All CM uncertainty analyses are based on manufacturer's specifications. Manufacturers specify accuracies in several ways. Some give absolute range of error, some give uncertainties as defined above, while others give rms errors. In this analysis, rms errors are multiplied by 2 . This results in confidence limits of approximately $95 \%$.

Data Acquisition Errors: The Campbell Scientific CR10 A/D converter accuracy is $\pm 0.2 \%$ of full scale range. The time base accuracy is \pm 1 minute per month, or about $23 \mathrm{ppm}$. The Site Data System checks the time-of-day clock once per day and corrects the CM clock if it is off by more than a minute.

Temperature: The accuracy of the temperature measurement is approximately $\pm 0.5 \mathrm{C}$. The long-term stability is not known. The radiation error of the naturally aspirated multi-plate radiation shield used for all stations is specified as $\pm 0.4 \mathrm{C}$ rms at $3 \mathrm{~m} / \mathrm{s}, \pm 0.7 \mathrm{C}$ rms at $2 \mathrm{~m} / \mathrm{s}$, and $\pm 1.5 \mathrm{C} \mathrm{rms}$ at $1 \mathrm{~m} / \mathrm{s}$.

The uncertainty with 95\% confidence of temperature sensors in naturally aspirated radiation shields is approximately:

- $\quad+/-0.6 \mathrm{C}$ when the wind speed is $6 \mathrm{~m} / \mathrm{s}$ or greater

- $\quad+/-1.0 \mathrm{C}$ when the wind speed is $3 \mathrm{~m} / \mathrm{s}$

- $\quad+/-1.5 \mathrm{C}$ when the wind speed is $2 \mathrm{~m} / \mathrm{s}$

- $\quad$ /-3.7 $\mathrm{C}$ when the wind speed is $1 \mathrm{~m} / \mathrm{s}$.

Relative Humidity (RH): The accuracy of the sensor is specified as $+/-2 \%$ RH for 10 to $100 \%$ RH, and +/-3\% RH for 0 to 10\% RH. Errors considered in this accuracy are calibration uncertainty, repeatability, hysteresis, temperature dependence, and long-term stability over a period of one year. The A/D conversion accuracy is equivalent to $+/-0.5 \% \mathrm{RH}$. 
The uncertainty with at least 95\% confidence is, therefore:

- $\quad+-2.06 \% \mathrm{RH}, 10$ to $100 \% \mathrm{RH}$

- $\quad+/-3.04 \% \mathrm{RH}, 0$ to $10 \% \mathrm{RH}$.

\subsubsection{Secondary/Underlying Variables}

This section is not applicable to this instrument.

\subsubsection{Diagnostic Variables}

Table 3.

\begin{tabular}{|c|c|c|}
\hline Quantity & Variable & $\begin{array}{c}\text { Measurement } \\
\text { Interval }\end{array}$ \\
\hline Standard Deviation of Dew Point Temperature & sd_td & $1 \mathrm{~min}$ \\
\hline Standard Deviation of Air Temperature & sd_temp & $1 \mathrm{~min}$ \\
\hline Standard Deviation of Relative Humidity & sd_rh & $1 \mathrm{~min}$ \\
\hline Battery Voltage & vbat & $1 \mathrm{~min}$ \\
\hline
\end{tabular}

\subsubsection{Data Quality Flags}

All CM observations are comprised of 3-second samples averaged over 1-minute, with the exception of battery voltage, which is a single sample made during the 1-minute period. All values are checked for values outside the range of sensor calibration or expected values.

Each qcmin is the decimal value of the binary string of bits set to $\mathbf{1}$ when the respective value is below the threshold. Similarly, each qcmax is the decimal value of the binary string of bits set to $\mathbf{1}$ when the respective value is above the threshold. Thus, if the nth bit is set, then $2^{* *}(\mathrm{n}-1)$ is added to the value of qcmin or qcmax.

Table 4.

\begin{tabular}{|c|c|c|c|c|c|}
\hline Quantity & Variable & $\begin{array}{c}\text { Measurement } \\
\text { Interval }\end{array}$ & Min & Max & Delta \\
\hline Dew Point & qc_td & $1 \mathrm{~min}$ & -40 & 50 & 2 \\
\hline Air Temperature & qc_temp & $1 \mathrm{~min}$ & -40 & 50 & 1 \\
\hline Relative Humidity & qc_rh & $1 \mathrm{~min}$ & -2 & 104 & 5 \\
\hline Battery Voltage & qc_vbat & $1 \mathrm{~min}$ & 0 & 20 & \\
\hline
\end{tabular}




\subsubsection{Dimension Variables}

Table 5.

\begin{tabular}{|c|c|c|}
\hline Variable & $\begin{array}{c}\text { Measurement } \\
\text { Interval }\end{array}$ & Unit \\
\hline base_time & 1 min & $\begin{array}{c}\text { seconds since YYYY-mm-dd } \\
\text { XX:XX:XX X:XX }\end{array}$ \\
\hline time_offset & 1 min & $\begin{array}{c}\text { seconds since YYYY-mm-dd } \\
\text { XX:XX:XX X:XX }\end{array}$ \\
\hline lat & 1 min & degrees \\
\hline lon & 1 min & degrees \\
\hline alt & 1 min & meters above sea level \\
\hline
\end{tabular}

\subsection{Annotated Examples}

This section is not applicable to this instrument.

\subsection{User Notes and Known Problems}

This section is not applicable to this instrument.

\subsection{Frequently Asked Questions}

What is the accuracy (quality) of the RH measurements?

The UNCERTAINTY of +/-2.06\% RH (10\% to $100 \% \mathrm{RH})$ or $+/-3.04 \% \mathrm{RH}(0 \%$ to $10 \% \mathrm{RH})$ is for a calibrated probe. The $\mathrm{RH}$ values reported by the probe normally drift slowly upward over time. Whenever a probe falls outside the range of uncertainty for a SIX-MONTH SENSOR VERIFICATION or reports values exceeding $104 \% \mathrm{RH}$, the probe is replaced by one that has been recently calibrated. Occasionally, a sensor will report values that are suspiciously low. A work order is then issued to perform a verification check and replacement if needed. A data quality report is issued for known erroneous data.

\section{Data Quality}

\subsection{Data Quality Health and Status}

This section is not applicable to this instrument.

\subsection{Data Reviews by Instrument Mentor}

- QC frequency: Daily

- QC delay: Weekly

- QC type: Comparisons, graphical plots 
- Inputs: Raw data

- Outputs: DQRs, summary reports

- Reference:

Data quality control procedures for this system were reasonably mature.

Graphical displays were generated and inspected on a weekly basis. Dew point temperature, relative humidity, and air temperature were routinely monitored. This procedure did not verify accuracy but did help identify suspected drifts in the sensors or sensor failure. When any data were suspect, a work request for investigation and/or sensor verification by SGP site operations personnel was issued. Every month, the entire CM T \& RH sensor was compared to secondary references. Summary reports were sent weekly to the SGP site scientist team. Biweekly checks on the temperature and relative humidity probes were now performed.

\subsection{Data Assessments by Site Scientist/Data Quality Office}

This section is not applicable to this instrument.

\subsection{Value-Added Procedures and Quality Measurement Experiments}

Many of the scientific needs of the ARM Program are met through the analysis and processing of existing data products into value-added products or VAPs. Despite extensive instrumentation deployed at the ARM sites, there will always be quantities of interest that are either impractical or impossible to measure directly or routinely. Physical models using ARM instrument data as inputs are implemented as VAPs and can help fill some of the unmet measurement needs of the program. Conversely, ARM produces some VAPs not to fill unmet measurement needs, but instead to improve the quality of existing measurements. In addition, when more than one measurement is available, ARM also produces "best estimate” VAPs. A special class of VAP called a Quality Measurement Experiment (QME) does not output geophysical parameters of scientific interest. Rather, a QME adds value to the input datastreams by providing for continuous assessment of the quality of the input data based on internal consistency checks, comparisons between independent similar measurements, or comparisons between measurement with modeled results, and so forth. For more information, see VAPs and QMEs web page.

\section{Instrument Details}

\subsection{Detailed Description}

\subsubsection{List of Components}

Dew Point: General Eastern Inc. D2 control unit, E4 chilled mirror sensor head.

Temperature and relative humidity sensor: Rotronic HPO-43 Humidity Temperature Probe, Rotronic Inc. 
Data logger: Campbell Scientific Model CR10 (or CR10X) Measurement \& Control Module and Model SM716 Storage Module, Precision: A function of input type and range, Uncertainty: $0.2 \%$ of Full Scale Range for Analog Inputs.

\subsubsection{System Configuration and Measurement Methods}

The CM system was located at the CF BBSS launch sites and was collocated with the Temperature, Humidity, Wind, and Pressure Sensors (THWAPS) system. The CM determines the ambient dew point by chilling a mirrored surface to until dew droplets form on the mirror surface. The presence of dew is detected optically and a small thermistor just under the mirror surface is taken to be the dew point. Thus, this instrument really measures the temperature of a mirror surface, which is presumed to be equal to the dew point temperature.

A Rotronic temperature and relative humidity sensor is used to check on the operation of the CM. The temperature and relative humidity are combined to give a dew point temperature or the dew point from the CM is combined with the Rotronic temperature to give a relative humidity. The temperature and relative humidity sensor is mounted in a naturally aspirated R. M. Young Model 41002 Gill Multi-plate Radiation Shield.

The data logger measures each input once every three seconds. The standard deviation each measurement is computed by the standard Campbell Scientific algorithm (P82 command). The 1-minute output includes dew point from the CM, T and RH from the Rotronic HPO-43, and standard deviation of each of quantity. In addition, battery voltage is sampled once per minute and this single sample is output.

\subsubsection{Specifications}

The specifications are given under Primary Variables and Expected Uncertainty, Section 5.1.1, and are further discussed under Definition of Uncertainty, Section 5.1.1.1.

\subsection{Theory of Operation}

Each of the primary measurements of dew point temperature, air temperature, and relative humidity are intended to represent self-standing data streams that can be used independently or in combinations. The theory of operation of each of these sensors is similar to that for sensors typically used in other conventional surface meteorological stations. Some details can be found under System Configuration and Measurement Methods, Section 7.1.2, but further, detailed description of theory of operation is not considered necessary for effective use of the data for these rather common types of measurements. The instrument mentor or the manufacturer can be contacted for further information.

A short description of the CM operation is given here (see Figure 1).

Dew (or frost) is detected optically by measuring the amount of light scattered by the dew (or frost). The mirror surface is heated or cooled until a uniform layer of dew (or frost) is on the mirror. 
Schematic of the Chilled Mirror Sensor

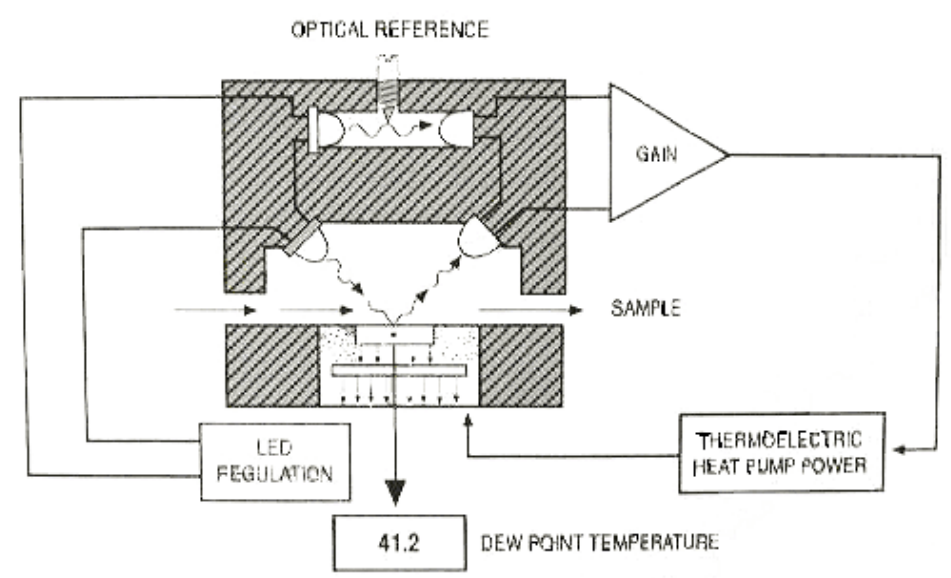

Figure 1.

\subsection{Calibration}

\subsubsection{Theory}

The CM is not calibrated as systems. The sensors and the data logger (which includes the analog-todigital converter) are calibrated separately. All systems are installed using components with a current calibration. The sensor calibrations are checked every month in the field by SGP site operations personnel by comparison to calibrated references. Any sensor that fails a field check is returned to the manufacturer for recalibration.

Air temperature and relative humidity calibrations are checked by comparison with a reference Vaisala Model HMI31 Digital Relative Humidity and Temperature Meter and HMP35 Probe. If the reported temperature and relative humidity vary by more than the sensor uncertainty from the reference, the probe is replaced by one with a current calibration.

\subsubsection{Procedures}

This section is not applicable to this instrument.

\subsubsection{History}

This section is not applicable to this instrument.

\subsection{Operation and Maintenance}

\subsubsection{User Manual}

This section is not applicable to this instrument. 


\subsubsection{Routine and Corrective Maintenance Documentation}

This section is not applicable to this instrument.

\subsubsection{Software Documentation}

ARM netCDF file header descriptions may be found at CM Data Object Design Changes and CMH Data Object Design Changes.

\subsubsection{Additional Documentation}

This section is not applicable to this instrument.

\subsection{Glossary}

Relative humidity - Percentage of saturated vapor pressure at the specified temperature.

Also see the ARM Glossary.

\subsection{Acronyms}

A-D: Analog to Digital converter ARM: Atmospheric Radiation Measurement

CM: Chilled Mirror

RH: Relative Humidity

SGP: Southern Great Plains

T \& RH: Temperature and Relative Humidity

Also see the ARM Acronyms and Abbreviations.

\subsection{Citable References}

Richardson, S.J., M.E. Splitt, and B.M. Lesht. 1999. Enhancement of ARM Surface Meteorological Observations During the Fall 1996 Water Vapor Intensive Observation Period. J. Atmos. Oceanic Tech., Vo. 17, No. 3, pp. 312-322.

Richardson, S.J., and R.O. Knuteson. 1999. A Chilled Mirror Dew Point Hygrometer for Field Use. In Proceedings of the Ninth ARM Science Team Meeting, Ed. Nancy Burleigh, U.S. Department of Energy, Washington, D.C. 